\title{
Health Literacy as a Complex Practice
}

\author{
JUDY HUNTER and MARGARET FRANKEN
}

\begin{abstract}
As attention to health literacy grows as an area for policy intervention, policy discourse continues to draw on skills deficit and patient compliance, buttressed by the dominant political discourse of individual responsibility. But for patients, the health domain is interwoven with linguistic challenges, significant affective issues, underlying cultural dimensions, political and economic exigencies, variable access to resources, and cognitive and situated complexity. From these perspectives, this article reports on findings of an ongoing study of health literacy demands in the Midlands region of the North Island of New Zealand, an area of high ethnic and socio-economic diversity. The study focuses on patients with diabetes and cardiovascular disease - two chronic areas strongly associated with 'failure to care' and identifed as having reached epidemic proportions. It analyses work to date: health professionals' conceptions of and responses to perceived patients' health literacy needs, and health information documents for patients. Implications of the study support the need for improvement in language and literacy skills among patients, but also the recognition of complexity and a collective responsibility for effective health communication.
\end{abstract}

\section{The context}

Over the past decade, the health care sector has driven international attention to health literacy, with several widely accepted tenets. Health literacy challenges are seen to affect a significant proportion of the population in Western developed countries (Nielsen-Bohlman, Panzer, and Kindig 2004, Nutbeam 1999). Low levels of health literacy are taken to correlate with a wide range of poor health outcomes for patients. For example, health researchers have found low health literacy associated with poorer general health relative to patients with higher levels of health literacy (Adams, Appleton, Hill, Dodd, Findley, and Wilson 2009), more hospital admissions (Adams et al. 2009, Paasche-Orlow and Wolf 2007), and poor management of chronic disease like diabetes (Osborn, Cavanaugh, Wallston, White, and Rothman 2009, Schillinger et al 2002). Low health literacy is seen to add significantly to a wide range of health care costs. Accordingly, there has been discussion and development of health literacy assessment tools (Bass, Jordan, Osbourne, and Buchbinder 2010, Parker et 
al. 1995), appropriately simplified information resources for patients, communication guides for health practitioners, and broad health literacy policies around health information (e.g., Doak, Doak, and Root 1996, The Scottish Government et al. 2009, U.S. Department of Health and Human Services, 2010, Wizowski, Harper, and Hutchins 2008). As noted above, most of this work has been conducted within the health care sector, with patients' comprehension of health information texts as the central focus.

In the current decade, government policy makers have increasingly turned their attention to health literacy, influenced by the work on literacy from the health care sector and concern about health care costs. This move also dovetails with the notion that literacy skills are linked to productivity and economic outcomes, as publicised through the OECD international literacy surveys of the 1990s-2000s. The literacy/economic prosperity paradigm has lifted the profile of adult literacy education dramatically. While this is a positive shift, health literacy is underpinned by a discourse of individual blame and deficit, along with a reductionist view of literacy. Adults with low literacy skills are labelled as unable to participate in $21^{\text {st }}$ century society. Their backgrounds are frequently characterised as consisting of school failure, dysfunctional families, addiction and crime, inadequate 'life skills' and employability skills. Low literacy is seen both as a central cause and consequence, rather than a possible complex correlate of these problems. The recent New Zealand Ministry of Health publication, Kōrero Mãrama: Health Literacy and Māori (2010) for example, is based on the findings of the most recent international literacy survey, Adult Literacy and Lifeskills (ALL). It highlights the large proportion of Māori with poor health literacy levels, that is, with 'insufficient skills to cope with the health literacy demands they typically face' (2010:9) and compares them to consistently higher non-Māori scores. On one hand, such an approach can help promote further efforts toward eliminating New Zealand's social inequalities. On the other hand, it reflects the dominant discourse driving literacy policy since the 1990s, that of individual blame and responsibility, together with a degree of cultural ascription.

It is important to note that these dominant discourses are not just the province of neoliberal policy makers. In an analysis of 257 adult literacy success stories over 35 years tracing the shift from public programme support to individualism, Sandlin and Clark (2009) maintain that adult literacy educators have also adopted the discourse of self-sufficiency and individual responsibility. Sandlin and Clark comment that the individualist discourse ultimately diminishes the important role of adult literacy education in people's lives.

At the same time, however, academic health literacy research, drawing on social practice perspectives of the last two decades, has also 
begun to challenge the dominant paradigm of skills deficits contributing to broader social and economic ills (Balatti, Black and Falk 2009, Freebody and Freiburg 1999, Nutbeam 1999, Papen and Walters 2008, Papen 2009). For example, Balatti, Black and Falk's research on health literacy and social capital has established the value of expanding social networks as resources in literacy learning. In the late 1990s, Freebody and Freiburg emphasised the important influence of the social sphere on literacy practices in health care:

The nature, value, significance and productivity of various literacy practices are shaped by the nature of the social relationship between institutional providers, such as doctors, and their clients. Literacy practices themselves derive their moral significance from the enactment and maintenance of institutional relationships within the local setting ... (1999:64)

More recently Papen and Walters' $(2008,2009)$ research on the social practices of health literacy has contributed significantly to our understanding of health literacy's social dimensions, by identifying a range of social factors that impact on health literacy and by acknowledging the importance of textual mediation of health care information. They found health literacy practices to be embedded both in hierarchical social relationships with medical authority figures and in institutional processes. They also found that patients drew on a range of information resources and their own social networks to help mediate health information. Issues of affect additionally influenced how patients received health information.

This work has shown that in the health domain, a reading and writing skills focus, even if contextualised to health information topics as in the Adult Literacy and Lifeskills Survey (ALLS), is inadequate for a conceptualisation of health literacy as understanding, accessing and using health information. While skills are clearly important, they are inadequate for conceptualising health literacy in use.

Our approach builds on Papen and Walters' health literacy project. It takes the perspective that health literacy presents complex cognitive, social, cultural and affective challenges for patients at multiple levels, including:

- disease domains and documentation,

- patient support, and

- the construction of patient identity

\section{The Health Literacy Project}

The researchers were approached by a not-for-profit health management organisation that supports the delivery of primary and community healthcare in the Midlands region of New Zealand - a region 
covering nearly half a million people enrolled in medical practices and an area of high ethnic and socio-economic diversity. The organisation had identified the goal of improving health literacy of patients as an important feature in their request to government to fund an extensive programme of research and development to improve the health outcomes of patients in the area. Of particular interest were cardiovascular health and diabetes, which are health conditions particularly associated with "at risk" communities in New Zealand such as Māori and Pasifika'. They saw that literacy researchers conducting research work with practitioners and patients in their region would support achievement of better health outcomes.

In our negotiation of the research work, we proposed a broad research approach to investigating health literacy, which included not only health care information texts, but also health practitioners, who provide and disseminate health care information, and patients, who are the users of that information. Although conventional responses to health literacy focus on health information texts, we believed that to identify the challenges patients face with health literacy, it was vital to include participants as well. We offered to subsequently develop two research-based sets of guidelines on communicating about health care, one for practitioners and one for patients.

We asked Midlands for samples of information that was typically given to GVD and diabetes patients, and we collected over one hundred health information documents from their general practice clinics. Most were published by agencies such as the New Zealand Heart Foundation or Diabetes New Zealand. To gain an overview of health care practitioners' perceptions of health literacy issues, we constructed an email questionnaire, which the Midlands Health Network sent to every practice. The promotion of the questionnaire and the approach to practices was mediated by the Midlands Health Network, the research funders, as per the contractual relationship for the project. We asked for participation from all the staff in each practice, potentially up to 1000 people, but received 143 responses. This is a seemingly low response rate, but those who did respond, in the main provided substantive comment.

The first set of questions was designed to establish whether the health sector recognized a local need for attention to health literacy, important at the policy level. It asked three questions about their views on the impact in New Zealand of internationally identified health literacy issues: efficient and equitable use of health services; effectiveness of preventative care for patients; and overall system-wide health costs. Over $60 \%$ of respondents rated these issues as having much or very much relevance in New Zealand. More importantly to us, the questionnaire also asked respondents to describe incidents where health literacy might have been an issue. The instruction stated: 'Please detail a specific event or situation where language, 
literacy, or numeracy appeared to play a part in a patient's ability to access and use health care services.' Respondents were prompted as follows: Who? (describe but don't name); What? (describe context and condition); Problem?; Outcome?

In the present paper, we report on data collection from Phase One of the project, an analysis of cardiovascular disease (CVD) and diabetes information texts collected from MHN's practices and an email questionnaire of staff in all the MHN practices. For the purposes of this paper we draw our examples from a single diabetes brochure, 'It's time to shed some light on ... Type 2 diabetes' (2005). Together these two complementary sets of findings create a rich image of the complexity of health literacy demands on patients.

\section{An overview of the two data sources}

The diabetes brochure, 'It's time to shed some light on ... Type 2 diabetes' (2005) has many features typical of the documents we collected. It is attractively presented, with colour photographs, diagrams, paragraphed print, contrasting headings, and ample white space. Headings in the brochures are brief or presented as questions patients might ask. Patients are directly addressed as you to create a personable, interactive tone. People in the photographs generally appear healthy and happy, physically active, and sociable. Images of fresh food appropriate for diabetics are colourfully presented. At the same time, various aspects of the text, particularly the language, were not inclusive to those considered most at risk.

The results of the incident description question provided data showing a range of difficulties, interpretations and responses to practitioners' and patients' experiences with health communication. Not surprisingly, many responses also reflected the widely-disseminated discourse of deficit, although practitioners' attitudes varied from supportive to unsympathetic. The findings of the two data sources will be discussed below as they contribute to a picture of health literacy challenges for patients.

\section{Disease complexity and the language of print information}

The semantic constituent analysisi of the GVD and diabetes texts showed two major types of information: explanations of the health condition and guidance on self-care.

The first step in our analysis of the brochure was to analyse the information 'topography'. We did this by means of mapping the information constituents against a taxonomy of constituents previously derived from an analysis of some one hundred cardiovascular and diabetes texts we analysed as part of a scoping project (see Franken Hunter \& Balmer, 2010).

The diabetes brochure covers 28 pages of text. All information constituents identified in our document analysis are presented in this 
brochure. Examples of constituents from different pages in the brochure are listed in Table 1 below.

What is immediately apparent is the complexity of information. One page of the brochure may be taken up with a single constituent. This occurs in the detailed information around diet, representing a response or intervention. Some pages contain almost all types of constituents. This type of information arrangement can be complex, as in the case of the pages explaining hypoglycaemia and hyperglycaemia, which link precise blood glucose measurements, general symptoms, timed recommendations about food intake, and a range of hypothetical preconditions.

\begin{tabular}{|l|l|}
\hline Information constituents & \\
\hline associated with condition & \\
\hline $\begin{array}{l}\text { definition of condition or aspects of } \\
\text { condition }\end{array}$ & $\begin{array}{l}\text { Type 1 diabetes is.. } \\
\text { Type 2 diabetes is... }\end{array}$ \\
\hline $\begin{array}{l}\text { causes: } \\
\text { physiological }\end{array}$ & $\begin{array}{l}\text { Insulin production is sluggish or the body is } \\
\text { resistant to insulin as a result of being } \\
\text { overweight }\end{array}$ \\
\hline Symptoms & $\begin{array}{l}\text { You may have type 2 diabetes for a long time } \\
\text { without symptoms }\end{array}$ \\
\hline Effects & $\begin{array}{l}\text { Long term complications - eye, kidney and } \\
\text { nerve damage }\end{array}$ \\
\hline associated with care & $\begin{array}{l}\text { Type 1 requires insulin } \\
\text { Type 2 is treated with lifestyle changes, } \\
\text { regular physical activity... } \\
\text { Tablets may be required }\end{array}$ \\
\hline responses/interventions & $\begin{array}{l}\text { Without a food plan and physical activity, } \\
\text { tablets won't keep glucose levels stable }\end{array}$ \\
\hline effects of responses/interventions & $\begin{array}{l}\text { You can prevent or delay long term damage } \\
\text { It cannot be cured but it can be controlled }\end{array}$ \\
\hline $\begin{array}{l}\text { status of/responsibility for } \\
\text { responses/interventions }\end{array}$ & $\begin{array}{l}\text { Take tablets if diabetes is not managed by } \\
\text { diet and exercise }\end{array}$ \\
\hline when to seek medical advice & $\begin{array}{l}\text { These tablets cause... } \\
\text { The following tablets do not cause... }\end{array}$ \\
\hline how/when to take medication & Check daily \\
\hline effects of medication & See your doctor nurse or dietitian \\
\hline monitoring of symptoms and \\
\hline sources of further advice
\end{tabular}

Table 1 Information Constituents in 'It's time to shed some light on ... Type 2 diabetes'

Note: The representation of constituents in the Table above are in some cases paraphrases of the way they are encoded in the text. 
However an initial analysis of information complexity only begins to touch on what potentially makes this healthcare text difficult for readers to understand. As well, the language of most texts we examined typically assumed educated readers who are competent and comfortable with complex sentence patterns and with specialised or infrequent vocabulary. The examples below, about conditions that can lead to undesirable outcomes, illustrate:

\section{Example 1}

If you require one of the tablets that can drop your blood glucose too low, of if you also require insulin to manage your diabetes, these medications will not enable you to keep good control of your blood glucose levels (2005:13).

\section{Example 2}

Even though you may require tablets or insulin to help control your blood glucose, if you regularly eat foods that are high in sugar and fat, or eat more food than your body requires for energy, you could experience hypoglycaemia (2005:5).

Both are cautionary statements that establish the importance of managing one of the significant effects of diabetes. As with other cautionary statements typically present in the brochure, the main clause depicts the possible negative consequence of patient treatments or actions. These are introduced with concessive and conditional clauses, coordinated by or with additional, alternative possibilities, each clause further modified with embedded phrases and clauses. Their presence assumes that patients can comfortably understand such sentence patterns. The examples are also illustrative of the complexity of vocabulary. Throughout, the presence of specialised medical terminology such as blood glucose, insulin, pancreas, and hypoglycaemia assumes that patients can comprehend easily. The brochure does contain a glossary, but the definitions offered do not necessarily mitigate the problem of specialised vocabulary. For example, insulin is defined as 'a hormone produced in the pancreas; helps glucose enter the body cells, where it is used for energy' (2005:28).

\section{Variable patient support and mediation of health information}

When health information texts are unclear, they raise further questions or omit critical information, patients may benefit greatly from another party explaining or 'mediating' the information. We found, however, that mediation of health information by health practitioners and 
social network support may be unpredictable and inconsistent. Responses to our questionnaire indicated a range of support for patients, which, on the part of practitioners, may have depended on the time available, the disposition of the practitioner and the availability of support agencies. The nature of practitioners' support for patients with difficulties varied widely. Some practitioners detailed lengthy interventions to help patients with limited literacy and few family resources; others were unable to intervene successfully.

The data included evidence of the limitations of service. One rural practitioner, expressed the exigencies of short staffing and high patient workload. The practice was 'always fully booked' and besieged by upset patients who needed to wait and who 'don't understand the pressure ... stressed tired Drs seeing too many patients in a day. Tired staff coping with upset demanding patients' (respondent 126). Our understanding from those in the sector is that medical practices are regularly working at, if not beyond, capacity.

\section{Health practitioner support}

Reports of practitioner interventions included help with navigating the health care system, individual support with form-filling, patient advocacy, brokering additional treatment, and reviewing and adjusting office procedures to meet new needs. Such inteventions nearly always involved additional work and follow-up. For example, one report described arrangements for an obese patient to join a hospital-based weight management programme. The patient was sent a questionnaire that he did not understand and did not complete, and so 'was taken off for consideration of this programme.' The respondent continued:

I contacted the adult weight management programme and asked that a copy of the questionnaire could be sent to the general practice, I then invited the patient in, went through questionnaire and completed it with and on behalf of the patient, the patient [was] then added back on programme. A lot of additional work and follow-up. Assumption is made that patient can read and understand questionnaires, etc that are sent out.

The diabetes brochure analysed above makes frequent references to sources to consult for further help or information (see Table 1, Sources of further advice). These include references to individuals with prescribed roles such as: doctor, nurse, diabetes nurse or specialist, dietitian, eye specialist, and podiatrist. A connection between these sources of help is expressed on 
one occasion when the document specifies, 'Your Doctor or Nurse can refer you to a Dietitian' On two occasions the notion of a team to support a patient is expressed as follows: 'your diabetes healthcare team' and 'talk with your healthcare team'. The information on sources of professional help expressed in this generalised way assumes that the patient is fully aware of the 'team', and would know how to access them - as well as the individuals identified. However, our questionnaire indicated that numbers of patients had difficulty understanding the health care system, hence did not access it fully.

One respondent (48) told of an 'elderly patient [who] injured his shoulder swinging from tree, given instructions on how and where to ring for an XRay and the process. The patient didn't inform radiologist that it was an accident and was given an appt for 10 days time.' As reported, the patient was in considerable pain, but thought that the delay was 'part of the system'. The practice identified the need for clear guidelines to support patients in what to say to the X Ray Department personnel, and conversely the need to support them to ask relevant questions of patients. Further, the practice aimed to make referral appointments for patients.

Practitioner respondents found, as well, that support for patients' diverse needs could prove challenging. For example, respondent 11 described the case of 'an Asian man who presented with a fish hook in his finger - was unable to give us any details.' The telephone interpreter services were unable to help, and eventually, the patient was 'sent to ED where they sought further help from alternative interpreters.'

\section{Patients' own support networks}

Black, Innes, and Chopra (2008) found wide networks of health information sharing among immigrant groups in their Australian study Patients' independently selected support networks are not acknowledged in the brochure. However, patients in our questionnaire were reported as using them, albeit in a variable or less than ideal manner. Several immigrant patients brought their children to translate; others relied on interpreter services, which weren't always available. One was reported to bring a friend to medical appointments.

Other patients, not identified as migrants, were reported to have difficulties. For instance, one respondent (68) described a patient who didn't 'understand the medico language given to them at hospital, no extended family there when explained, don't realise the importance of taking [warfarin] and testing regularly.' The result was hospital re-admission. Another poignant example was an 'older Māori lady ... unable to read.' She had no phone, no transportation, no other adults in her home, and three children to care for. She was unable to read posted notices for breast screening appointments, and so did not attend. The health practitioner 
negotiated repeatedly with the patient, the breast screening clinic, and later with the hospital oncology department to support her and find ways for her to recognise and respond to posted health information. Overall, then, these snapshots suggest that both migrants and local residents experience uneven support.

The brochure we analysed urges patients to 'ask family and friends for help' or the 'diabetes society support group' - in an unspecified way. The patients would arguably benefit from knowing what the support group can offer, and also how family and friends could potentially help.

\section{Issues of patient identity}

\section{Practitioners' construction of patients}

We received many questionnaire responses indicating sympathetic, supportive attitudes toward patients with difficulties managing their condition. The following comments about an Indian woman newly diagnosed with diabetes illustrate:

Couldn't read information we could supply to reinforce teaching. There is a lot to take in all at once. This required many more visits and extensive follow-up. (respondent 39)

Despite the extra work entailed in supporting this patient, the practitioner took an understanding perspective. Judging from the entry above, the patient was presented as someone struggling with a great deal of new information. The following patient, however, was depicted as unresponsive to self-care education, and a negative attitude is implied. His noncompliant behaviour is linked to welfare dependency, an alcohol problem, as well as gout attacks.

Middle aged Maori Male. Uncontrolled gout, frequent gout attacks at least monthly. Not compliant with medications. On sickness benefit because of this. Severe alcohol problem. Did not respond to repeated education and was still non compliant. [Outcome?] Poor (respondent 81)

One respondent stood out as highly negatively disposed toward the notion of health literacy issues and also to patients who experience them:

There is no problem created by people with nothing else to dodo gooders, tree huggers \& societies bluggers [sic] anyone not able to access health care is a lazy, ignorant individual not worth anyones trouble (respondent 64). 
Although this attitude was extreme in the data, the negative labelling that characterises those with health literacy challenges as unworthy is often echoed in the popular press and political discourse of individual blame.

Our data showed no evidence of diminished treatment of patients who did not take up health care education. It did however suggest frustration and resentment on the part of practitioners at spending time and energy on supporting patients who appeared not to be self-motivated. On the other hand, as in the example above, those patients who were seen to be trying or failing through no fault of their own (e.g., inability to read documents) were often reported to receive willing extra support.

The discourse of patient responsibility for self-care similarly permeated the health texts we analysed. The diabetes brochure states the philosophy of self-management explicitly in the closing:

Diabetes puts you in the driving seat. You are in charge of the daily decisions and what road you take to manage your health. ... Approximately 95\% of diabetes care is self-care (2005:26-7)

The final photo in the brochure shows a pensive white-haired man leaning on a fence. Absent from such images and the associated discourse is acknowledgement of patient diversity and knowledge. Like the white male image, Western medical knowledge dominates over folk knowledge or indigenous knowledge. Also lacking is any consideration of the complexities of the health care system including the still developing paradigm of care for chronic disease.

\section{Patient affect and dignity}

Turner and Kelly (2000) maintain that the emotional aspects of chronic disease are underplayed in the health sector and that medical providers are often ill-equipped to deal with them. Many of the health information texts did however acknowledge the emotional stress of being diagnosed with GVD or diabetes but in a superficial or 'light' way. They gave tips for beating depression or advice to draw on friends or family for support. The diabetes brochure encourages newly diagnosed patients who 'may feel anxious, sad, or angry' ... [to] give yourself a "pat" on the back for your successful [lifestyle] changes' (2005:26). Such an approach may be reductionist and misleading. Bundesmann and Kaplowitz (2010) make clear for instance that self-care for diabetes patients is a 'constant challenge'.

Practitioners reported patients who were not only emotionally affected by their disease, but also by their embarrassment at not 
understanding health information, as in the following response about a patient trying to explain his needs to the practice receptionist:

[He] was very hard to understand, I think he had a cleft pallet [sic] and because he was having to repeat himself he was finding it frustrating as well as embarrassing in front of the entire waiting room full of patients. I took the patient into my office where he could feel comfortable and had all the time in the world to make himself clear (95).

Another respondent commented on the dilemma common to many with low literacy levels:

People who aren't very literate have huge problems filling in the multiple forms required by WINZ [Work and Income NZ] ACG [Accident compensation Corporation]. They sometimes don't attend these places or get the help they are entitled to because it is too stressful for them or they don't tell anyone they can't fill out the paperwork (113).

\section{Gultural and linguistic diversity}

Diversity was not a strong feature of the health information texts we viewed. Diverse cultural traditions and values in nearly all the documents were recognised primarily by including non-traditional food names and photos of patients who were seemingly from Māori or Pasifika backgrounds. The diabetes brochure analysed here contains seventeen photos of people. Fourteen seem to be recognisably white, which does not reflect the degree of concern about the high prevalence of diabetes among the Māori population (Ministry of Health 2010). This brochure includes only taro (common to Pasifika people) as a food outside the dominant culture. A diagram of a plate of food shows ideal relative proportions of a traditional meat-and-twovegetables meal. Health information texts in a variety of languages do exist, but they are few, and we have not surveyed them. However we do know that by and large the visual material is replicated.

Questionnaire respondents reported communication difficulties with immigrant patients. A few were able to contact interpreter services for patients. Others described children accompanying parents to doctor visits and having to translate intimate health information. There was concern about children missing school as well as perhaps not interpreting information accurately. Practitioners' responses ranged from not charging a patient for a visit where communication failed to, in some cases, frustration: 
'Do new immigrants have to pass a literacy test? Surely everyone should have to pass a certain standard before entering NZ' (respondent 134). Some respondents recognised the possibility of different cultural attitudes toward health care; nevertheless they did not seem to be confident of their own interpretations of cultural aspects of patient behaviour.

Although not a part of our research, one promising development is the One Heart Many Lives (He Manawa Tahi Koiora Tini) programme and website (http://www.oneheartmanylives.co.nz/), sponsored by PHARMAC, the Pharmaceutical Management Agency, a crown agency of the Ministry of Health. The programme is specifically aimed at Māori and Pacific Islands men, with the slogan, 'Get a heart check, bro'. It is designed to promote heart health awareness, heart checks and action to deal with any diagnosed heart problems. A key feature of the website is inspirational stories by Māori and Pasifika men who are actively taking control of their heart health. These stories, told by the men themselves, are in video format as well as in print with photos. However, the dominant discourse of individual responsibility remains, as well as the question of accessibility for those without easy internet access. Nevertheless, in our view, the programme constitutes an important step in appreciating the dignity and identity of people rather than marking them as deficient.

\section{Conclusions and implications for health literacy education}

Interpretations of the ALLS survey (e.g. Ministry of Health 2010) depict health literacy simplistically. Health literacy is seen as needing adequate reading levels for health-related documents, as being the responsibility of individuals, and as being associated with particular cultural groups. Yet if we take health literacy as patients' 'ability to understand, access, and use health-related tools and services in a given location' (Papen and Walters 2008:10), then as this study has shown, it is clearly a much more complex issue.

The health information documents we examined displayed syntactic and information complexity, together with specialised and infrequent vocabulary items. We maintain that texts displaying such text features are considerably more accessible to educated middle-class members of the dominant white population in New Zealand than to those of the nondominant population. The fact that effective uptake of health information is represented largely as the responsibility of individual patients, reflects the dominant discourse of literacy deficit. We need to recognise, however, that the wording of our question, '.. an event or situation where language, literacy, or numeracy appeared to play a part in a patient's ability to access and use health care services' may have contributed to the responses. With diseases as complex as diabetes, patients are doubly challenged to cope with their condition. In sum, health-related texts appear 
to pose greatest challenges for those segments of the population considered to be most in need.

The study has also shown that patients have variable access to support and mediation of health information. Health practitioners may not always have the time or resources to support patients in the ways many of our respondents described. Patients' individual social networks, which help them share information and provide material and emotional support, are also variable. As noted by Black, Innes and Meenakshi (2008), some immigrant groups have well-established, wide networks that serve as ample social capital. But our questionnaire, albeit focussed on difficulties, provided evidence that immigrant support networks were limited, at least in medical treatment encounters. Moreover, questionnaire respondents also described a number of Māori patients with limited support networks.

Practitioners' views of the extent to which patients were motivated to comply with self-management regimes appeared to influence their dispositions toward patients. One expressed highly negative views of patients with communication difficulties, labelling them lazy bludgers, providing at least some evidence of possible stereotyping (see Hill 2010, for example). Issues of patient identity also appeared to impact on patients' access to health information in several ways. Most of the health information texts we analysed minimally acknowledged New Zealand's population diversity. Immigrant patients who were not proficient in English seemed to have ad hoc arrangements for interpreting, relying on children, friends, or agencies that weren't always available. Health care respondents referred to embarrassment and anxiety observed in patients over lack of understanding and disabilities. The brochure acknowledged but minimised the emotional impact of diabetes on patients. Finally both questionnaire respondents and health information texts presented relatively positive images of informed patients who readily and competently self-managed their disease, were able to overcome minor distress, and were served by a ready, knowledgeable health support sector.

In sum, the study has suggested that the language and content of health information documents favour white, middle-class, educated patients who are predisposed to comply with medical advice. Moreover, the above discussion shows that access to health care support and mediation of information is influenced by additional factors that marginalised patients especially may not be aware of or be able to control. All these factors may coalesce to further disadvantage patients with low health literacy, poor health, and social, economic, and educational disadvantage.

The research may have implications beyond cardiovascular disease and diabetes. Increasing chronic disease worldwide has meant new challenges for the health sector, that is, a need for long-term care in times of 
limited public health resourcing in developed as well as developing countries. In the words of a recent United Nations report:

While non-communicable diseases have traditionally afflicted mostly high income populations, current evidence shows that the spread of such diseases is associated with increasing levels of development. Death and disease from non-communicable diseases now outstrip communicable diseases in every region except Africa, where the rate of such diseases is quickly rising. By 2030, non-communicable diseases are projected to cause nearly five times as many deaths as communicable diseases worldwide, including in low- and middle-income countries. (Secretary General, 2011:2).

In effect, the UN statement throws the issue into relief. While this situation implies on-going health care needs and calls for greater urgency, the prevailing orthodoxy of individual health literacy as reading skills alone cannot stand as a discrete component of what is a complex, multifaceted problem.

\section{What is the role of literacy educators?}

One important initiative is for literacy and numeracy educators to work together with the health sector to develop and deliver health literacy resources and programmes, like the current Health Literacy Project and like the work begun in Australia, Canada and the US (Black, Innes and Chopra 2008, Neilson-Bohlman, Pnazar and Kindig 2004, The Centre for Literacy nd). Such work would build on the international development in vocational and workplace literacy pedagogy of embedding, or integration of literacy teaching with vocational education, based on the understanding that literacy is best learned in the context of use (Casey et al 2006, Sefton, Waterhouse and Deakin 1994). Casey et al's (2006) research at the NRDG in London showed that jointly-planned team teaching between literacy and numeracy educators and vocational educators had the best results for learners, for it drew optimally on the expertise of each sector. Implementation of such approaches is not necessarily straightforward, however. For example, anecdotal evidence from New Zealand suggests that much literacy embedding in joint vocational/literacy teaching practice is operationalised simply as decoding key texts with an emphasis on specialised vocabulary. Black and Yasukawa (2011) report similar findings in their study of Australian vocational education courses. What is critically important in the context of healthcare is the recognition of the need for expert knowledge. And this demands a true partnership with literacy experts and those from the field of medicine. This has to date not been an unproblematic connection.

Another important approach, which would circumvent the deficit image of patients, is to support patients as agents in their health care. This means more than the Ask Me 3 campaign (1. What is my main problem? 2. 
What do I need to do? 3. Why is it important for me to do this?) conducted by the American National Patient Safety Foundation (nd). While the programme encourages patients to ask questions of their physicians, it still constructs them as people who above all need to be compliant to doctors. Moreover, Zarcadoolas (2010) points out that teaching low literacy patients to 'parrot' simple questions is unlikely to improve treatment compliance or doctors' clear communication, and it may perpetuate stereotypes about those with low literacy.

Patient agency, rather, would involve knowledge and strategies for navigating the health care system, for critically analysing health texts, and for taking the initiative in identifying and engaging support networks. These measures do not imply a confrontational approach. Rather, they aim to support patients as owners of their health, who have the capability to search out information as they need it, make informed decisions and enlist the expertise of the health sector. In the spirit of critical discourse analysis, critical analysis of health texts, for literacy practitioners, document designers, and for patients, involves understanding the underlying identities and ideologies constructed by the texts, so that patients do not need to internalise their marginalisation as normal.

Health literacy could easily develop along a path that not only constructs marginalised people as deficient literacy learners but as patients responsible for their own poor health. Patients deserve to be treated as worthy agents facing a complex social system, new knowledge, the imposition of new life styles, and new demands on resources. The challenge for the health system as a whole is to construct a comprehensive, inclusive, enabling, and interactive approach to health literacy.

\section{References}

Adams, RJ, Appleton, S I, Hill, C L, Dodd, M, Findlay, C, and Wilson, D H (2009) Risks Associated with Low Functional Health Literacy in an Australian Population, Medical Fournal of Australia, vol 191, pp 530534.

Baker, D, Gazmararian, J, Williams, M, Scott, T, Parker, R, Green, D, Ren, J, and Peel, J (2002) Functional Health Literacy and the Risk of Hospital Admission among Medicare Managed Care Enrolees, American Fournal of Public Health, vol 92, no 8, pp 1278-1283.

Balatti, Jo, Black, Stephen, and Falk, Ian (2009) A New Social Capital Paradigm for Adult Literacy: Partnerships, policy and pedagogy, NCVER, Adelaide.

Bass III, Pat, Wilson, John and Griffith, Charles (2002) A Shortened Instrument for Literacy Screening, Fournal of General Internal Medicine, vol 18, pp 1036-1038. 
Black, Stephen, Innes, Christine, and Meenakshi, Chopra (2008) Diabetes Literacy: A partnership approach to educating culturally and linguistically diverse people about the risks and prevention of type 2 diabetes, TAFE NSW Northern Syney Institute and Northern Sydney Central Coast Area Health Service, Sydney.

Black, Stephen \& Yasukawa, Keiko (2011) Beyond deficit approaches to teaching and learning: Literacy and numeracy in VET courses, Rendezvous Hotel, Melbourne, April 2011, in Bringing Australia's VET research community together, AVETRA executive, ed, AVETRA, retrieved 4 July 2011 from http://avetra.org.au/wpcontent/uploads/2011/05/62.00.pdf

Bundesmann, R and Kaplowitz, S (2011) Provider Communication and Patient Participation in Diabetes Self-care, Patient Education and Counseling, vol 85, no 2, 143-147, retrieved 7 October 201 lhttp://www.ncbi.nlm.nih.gov/pubmed/21035296\#

Casey, H, Olga, C, Eldred, J, Grief, S, Hodge, R, Ivanic, R, Jupp, T, Lopez, D, and McNeil, B (2006) You Wouldn't Expect a Maths Teacher to Teach Plastering: Embedding literacy and language in post 16 vocational programmes - the impact on learning and achievement, National Research and Development Centre for Adult Literacy and Numeracy, London.

Diabetes New Zealand (2005) It's time to shed some light on ... Type 2 diabetes, Wellington, NZ.

Doak, C, Doak, L, and Root J (1996) Teaching patients with low literacy skills, 2nd ed, J B Lippincott, Philadelphia, PA.

Freebody, Peter and Freiberg, Jill (1999) Health Literacy and Social Practice: Response to Nutbeam, Literacy and Numeracy Studies, vol 9, no 2, pp 57-66, retrieved from http://search.informit.com.au.ezproxy.waikato.ac.nz/fullText; $\mathrm{dn}=2$ 00105398;res=AP

Hill, T E (2010) How Clinicians Make (or Avoid) Moral Judgments of Patients: Implications of the evidence for relationships and research, Philosophy, Ethics and Humanities in Medicine, vol 5, no 11, retrieved 9 October 2011 from http://www.ncbi.nlm.nih.gov/pmc/articles/PMC2914676/. doi: 10.1186/1747-5341-5-11.

Johns, T and Davies, F (1983) Text as a Vehicle for Information: The classroom use of texts in teaching reading in a foreign language, Reading in a Foreign Language, vol 1, pp 1-19.

Ministry of Health (2010) Kōrero Mārama Health Literacy and Māori: Results from the 2006 Adult Literacy and Life Skills Survey, retrieved 27 March 2010 from http://www.moh.govt.nz/moh.nsf/pagesmh/9932/\$File/koreromarama.pdf 
National Patient Safety Foundation (nd) Ask Me 3, retrieved 30 September 2011 from http://www.npsf.org/askme3/

Nielsen-Bohlman, Lynn, Panzer, Allison, Kindig, David, eds (2004) Health Literacy: A Prescription to End Confusion, Report Brief, Washington, DC: National Academies Press. Retrieved 7 December 2010 from

http://www.iom.edu/Reports/2004/Health-Literacy-A-Prescription-toEnd-Confusion.aspx

Nutbeam, Don (1999) Literacies Across the Lifespan, Literacy and Numeracy Studies, vol 9, no 2, pp 47-55.

Osborne, H (2010) In other words... Screening for health literacy using the newest vital sign, retrieved from http://www.healthliteracy.com/article.asp?PageID=6766

Paasche-Orlow, M K and Wolf, M S (2007) The Causal Pathways Linking Health Literacy to Health Outcomes, American Fournal of Health Behavior, vol 31, pp 19-26.

Paltridge, B (1995) Analyzing genre: A relational perspective, System, vol 23, no 4, pp 503-511.

Papen, Uta (2009) Literacy, learning and health: A social practices view of health literacy, Literacy and Numeracy Studies, vol 16, no 2, vol 17, no 1, pp 19-34.

Papen, Uta and Walters, Sarah (2008) Understanding Literacy and Health, NRDC, London, retrieved from http://www.nrdc.org.uk

Parker, Ruth, Baker, David, Williams, Mark and Nurss, Joanne (1995) The Test of Functional Health Literacy in Adults, Fournal of General Internal Medicine, vol 10, no 10, pp 537-541.

Sandlin, J and Clark, M (2009) From Opportunity to Responsibility: Political master narratives, social policy, and success stories in adult literacy education, Teachers College Record, vol 111, no 4, pp 999-1029.

Schillinger, D, Grumbach, K, Piette, J, Wang, F, Osmond, D, Daher, C, Palacios, J, Diaz Sullivan, G, and Bindman, A B (2002) Association of Health Literacy with Diabetes Outcomes, Fournal of the American Medical Association, vol 288, no 4, pp 475-482.

Secretary General of the UN (2011, May). Prevention and control of noncommunicable diseases, United Nations General Assembly, New York.

Sefton, R, Waterhouse, P, and Deakin, R (1994). Breathing Life into Training: A model of integrated training, National Automotive Industry Training Board, Melbourne.

The Centre for Literacy (nd) Health Literacy, retrieved 7 October 2011 from http://www.centreforliteracy.qc.ca/health_literacy

The Scottish Government \& Jennifer Waterton Consultancy. (2009). Health Literacy - A scoping study final report, Scotland, retrieved 22 September 2010 from www.scotland.gov.uk/Resource/Doc/296717/0092261.pdf 
Turner, Jane and Kelly, Brian (2000) Emotional Dimensions of Chronic Disease, Western Fournal of Medicine, vol 172, no 2, pp 124-128.

U.S. Department of Health and Human Services, Office of Disease Prevention and Health Promotion (2010) National Action Plan to Improve Health Literacy, Washington, DC, retrieved from http://www.health.gov/communication/HLActionPlan/

Ventola, Eija (1987) The Structure of Social Interaction: A systemic approach to the semiotics of service encounter interaction, Pinter, London.

Weiss, B D, Mays, M Z, Martz, W, Castro, K M, DeWalt, D A, Pignone, M P, Mockbee, J, and Hale, F A (2005) Quick Assessment of Literacy in Primary Care: The newest vital sign, Annals of Family Medicine, vol 3, no 6, pp 514-522.

Wizowski, Lindsay, Harper, Teresa, Hutchins, Tracy (2008) Writing health information for patients and families, $3^{\text {rd }}$ ed , Hamilton Health Sciences, Hamilton, Canada, retrieved 15 February 2011 from www.hamiltonhealthsciences.ca

Zarcadoolas, Christina (2010) Ask Me 3 Fails to Live up to its Billing, retrieved 10 October 2011 from http://publichealthliteracy.blogspot.com/2010/03/ask-me-3-fails-tolive-up-to-its.html

\section{Acknowledgments}

This project was funded by the Midlands Health Network through a research project with the University of Waikato. The views expressed are those of the authors and do not necessarily represent those of the Midlands Health Network. 


\section{Endnote}

i The term constituents has been used to refer to structural elements in genre analysis (Paltridge 1995, Ventola 1987); or in the analysis of text types (Johns \& Davies 1983). 